\title{
Aspergillus flavus Biomass in Maize Estimated by Quantitative Real-Time Polymerase Chain Reaction Is Strongly Correlated with Aflatoxin Concentration
}

\author{
Santiago X. Mideros, Department of Plant Pathology and Plant-Microbe Biology, Cornell University, Ithaca, NY \\ 14853; Gary L. Windham and W. Paul Williams, United States Department of Agriculture-Agricultural Research \\ Service, Corn Host Plant Resistance Research Unit, Mississippi State, MS 39762; and Rebecca J. Nelson, Depart- \\ ment of Plant Pathology and Plant-Microbe Biology and Department of Plant Breeding and Genetics, Cornell Uni- \\ versity, Ithaca, NY 14853
}

\begin{abstract}
Mideros, S. X., Windham, G. L., Williams, W. P., and Nelson, R. J. 2009. Aspergillus flavus biomass in maize estimated by quantitative real-time polymerase chain reaction is strongly correlated with aflatoxin concentration. Plant Dis. 93:1163-1170.

Aspergillus flavus causes ear rot of maize and produces aflatoxins that can contaminate grain even in the absence of visible symptoms of infection. Resistance to aflatoxin accumulation and pathogen colonization are considered distinct traits in maize. Colonization of grain by fungi such as A. flavus has been difficult to quantify. We developed and validated two quantitative real-time polymerase chain reaction (qPCR) assays to estimate fungal biomass in maize tissues. In order to study the relationship between fungal biomass and aflatoxin accumulation, qPCR was conducted and aflatoxin concentrations were assayed in milled samples of mature maize kernels for two diverse sets of maize germplasm. The first was a set of hybrids that was inoculated with $A$. flavus in a conducive field environment in Mississippi. These hybrids, mainly early tropical and non-stiff-stalk genotypes adapted to local conditions, carry known sources of resistance among their progenitors. The second set, also tested in Mississippi, was a group of inbred lines representing a wider sample of maize genetic diversity. For both sets, our results showed a high correlation between fungal load and aflatoxin concentration in maize kernels. Our qPCR methodology could have a direct impact on breeding programs that aim to identify lines with resistance to aflatoxin accumulation, and set the stage for future studies on the genetic dissection of aflatoxinrelated traits.
\end{abstract}

Aspergillus flavus Link is a widely distributed fungus that spends most of its life cycle as a saprophyte in the soil (30). It is also an opportunistic pathogen that is able, under certain conditions, to cause diseases in plants and animals, including maize (Zea mays L. subsp. mays) and humans $(8,13)$. A. flavus is a common cause of ear rot of maize in warm climates. This fungus can also contaminate a number of agricultural commodities with a wide array of secondary metabolites, some of which are toxic to humans and farm animals. Of particular relevance are aflatoxins produced by some strains of A. flavus, A. parasiticus, and $A$. nominus. Aflatoxins are polyketides that often accumulate in infected plant seed such as maize kernels or

Corresponding author: R. J. Nelson

E-mail: rjn7@cornell.edu

Mention of trade names or commercial products in this publication is solely for the purpose of providing specific information and does not imply recommendation or endorsement by United States Department of Agriculture.

Accepted for publication 12 July 2009.

doi:10.1094/PDIS-93-11-1163

(C) 2009 The American Phytopathological Society peanut (30). The B1 form of aflatoxin is the most potent carcinogen found in nature. While moderate exposure leads to cancer in humans, acute aflatoxicosis causes direct liver damage that often results in cirrhosis $(15,40)$. Perhaps more important and not as widely reported are the effects of chronic exposure, which cause immunosuppression and nutritional interference (39).

The strict regulation on trade of contaminated maize leads to economic burdens on farmers in developed countries. In developing countries, where regulations may be nonexistent or not enforced and where consumption of homegrown maize is typical, people may be widely exposed to this toxin. High concentrations of aflatoxins are consumed by humans in areas of the world that have higher than average levels of liver cancer, childhood malnutrition, and disease. Many of these health problems interact with and are exacerbated by aflatoxicosis, increasing morbidity or mortality (33). For example, aflatoxin and the hepatitis B virus have synergistic effects in causing liver cancer $(15,40)$.

A. flavus conidia are the primary source of inoculum and infect developing maize ears. Cytological studies indicate that the silk tissue after pollination is the primary portal of entry into the maize ear (22).
Mycelium then colonizes the young kernels through the rachilla. It has been observed that the pathogen destroys the cells ahead of itself in a typical necrotrophic interaction (34). High temperatures $\left(>30^{\circ} \mathrm{C}\right)$ and drought favor the development of this disease (30).

Control measures generally consist of preharvest cultural practices that reduce plant stress, periharvest practices that reduce grain moisture, and postharvest management practices that maintain low grain humidity and avoid pest infestation. However, cultural practices have a limited effect, especially with preharvest aflatoxin contamination. The development of preharvest host resistance to aflatoxin contamination is an important component of integrated management (25). Progress on this strategy has been limited, however, due in part to the complexity of this trait. Aflatoxin resistance behaves as a quantitative trait, which presents relatively low levels of heritability and extremely high environmental effects. Maize lines with high degrees of resistance have been identified and low-resolution quantitative trait loci (QTL) maps have been generated for reduced aflatoxin accumulation and Aspergillus ear rot resistance $(2,6,27,38)$. These forms of resistance have not been consistently incorporated into elite maize lines.

Resistance to A. flavus kernel infection and accumulation of aflatoxin may be seen as distinct traits $(24,46)$. Two reports examining the relationship between the two traits suggested strong but variable correlations $(29,36)$, whereas a third study indicated that the two traits were independent (4). An African inbred found to be resistant to aflatoxin production allowed high levels of $A$. flavus growth, as measured using a $\beta$ glucuronidase (GUS)-transformed strain. In addition, certain inbreds that were found to be susceptible to aflatoxin accumulation supported low levels of fungal growth (4). There is also indirect evidence from QTL mapping experiments in which loci affecting ear rot and aflatoxin accumulation were associated with different molecular markers, suggesting that the loci mapped to distinct chromosomal regions (6). Further support for the separate nature of fungal growth and aflatoxin accumulation was inferred from the effect of antioxidant 
compounds such as caffeic acid on A. fla$v u s$ in culture, which reduced aflatoxin content more than $95 \%$ while fungal weight on membrane filters was unaltered. Microarray analysis indicated that genes in the biosynthetic pathway of aflatoxins were significantly downregulated in the presence of caffeic acid (19). It has been recently proposed that aflatoxigenesis is a fungal reaction to oxidative stress $(18,19)$. It is possible that maize lines that produce more reactive oxygen species (ROS) in response to Aspergillus spp. infection accumulate higher concentrations of aflatoxins.

Further exploration of this and related hypotheses requires sensitive tools for the measurement of both aflatoxin and $\mathrm{A}$. flavus. Enzyme-linked immunosorbent assays (ELISAs) are available for the measurement of aflatoxin but tools are needed that allow efficient and specific measurement of fungal biomass. Conventional assessment methods for Aspergillus ear rot do not provide accurate evaluations of the levels of infection because they only allow rating of the superficial signs of the fungus. Percent ear rot has the disadvantage of subjectivity, which adds error to the already environmentally affected trait. Accurate measurements can be achieved using transformed strains of A. flavus that express either GUS or green fluorescent protein (GFP) $(3,11,29)$ but the use of transgenic strains in the field requires compliance with regulatory guidelines and limits the range of strains that may be utilized. For these reasons, we developed a quantitative real-time polymerase chain reaction (qPCR) technique for the evaluation of infection levels in maize kernels.

qPCR is a modification of the traditional PCR that measures the amount of amplification product at every cycle of the reaction. Two different florescent dyes can be used to measure the increase of PCR product. The SYBR green dye binds to doublestranded DNA and the fluorescence increases as a result of the logarithmic growth of the target sequence. The other method is the use of TaqMan sequencespecific probes with dual fluorochromes $(1,14)$. One of these labels is a reporter (such as VIC or FAM) and the other is a quencher (TAMRA). Due to physical proximity of the reporter to the quencher, the probe is not fluorescent until the polymerase separates the two labels during each of the amplification cycles. The fluorescence due to SYBR green or the reporter dyes in the TaqMan reactions is measured after every replication cycle of the PCR. When this fluorescence exceeds a specific threshold, a cycle threshold $(\mathrm{Ct})$ value is produced. This $\mathrm{Ct}$ value is compared with a standard curve of known quantities of DNA and the concentration of DNA in the unknown sample can be inferred $(1,14)$. Pathogen DNA concentration in a sample of host tissue can be used as an estimator of fungal biomass $(1,28)$. Re- cently, a TaqMan qPCR technique was used to quantify A. flavus in pure culture but its use in the presence of DNA from other species, including corn, in the same sample was not validated (9).

In this article, we report the development and validation of two quantitative qPCR techniques for the accurate estimation of fungal colonization in maize grain. One important application of this assay is in characterizing the nature of aflatoxin in maize germplasm. In particular, it is of considerable practical and biological interest to determine whether there are maize genotypes that reduce the levels of colonization of A. flavus without triggering the accumulation of high aflatoxin concentrations and, conversely, whether maize genotypes exist that suppress fungal growth while inducing toxin accumulation. Because there is evidence for the induction of aflatoxin production by ROS and a reduction in the toxin concentration caused by certain antioxidants (17), we tested the hypothesis that different types of A. flavus resistance have differential effects on fungal biomass and aflatoxin accumulation. For this purpose, we used the TaqMan method developed in the first part of the study to analyze both aflatoxin concentrations and fungal DNA concentrations on hybrids that were field inoculated in Mississippi. The parents of these hybrids contain early tropical and non-stiff-stalk maize lines as defined by a genetic diversity study by Liu et al. (21) and are maintained by the United States Department of Agriculture-Agricultural Research Service (USDA-ARS) Corn Host Plant Resistance Research Unit at Mississippi State University. Because the strong correlation found on these hybrids could have been attributed to common sources of resistance, we subsequently tested a set of 18 diverse inbred lines. These inbreds are a subset of the founders of the "nested association mapping" population that have been developed to maximize the number of alleles captured for quantitative genetics studies (45). These genotypes contained not only tropical and non-stiff-stalk maize lines but also stiff-stalk lines and lines with mixed ancestry $(12,21)$.

\section{MATERIALS AND METHODS}

Primers and TaqMan probes. Three pairs of A. flavus-specific primers and their respective probes were designed in the internal transcribed spacer 1 (ITS1) using Primer Express 1.5 (Applied Biosystems, Foster City, CA). Sequences of the ITS1 regions were obtained from GenBank for A. flavus (AB000532) and the closely related species $A$. oryzae (AB00533), A. sojae (D84357), A. parasiticus (D84356), A. tamarii (D84358), and Emericella nidulans (AB243115) (30,37). The sequences were aligned with ClustalX 1.81 (35). Primers were designed to correspond to regions with the highest polymorphism between species as indicated by ClustalX. Primer pair Af2 (forward primer: 5'ATCATTACCGAGTGTAGGGTTCCT-3'; reverse primer: 5'-GCCGAAGCAACT AAGGTACAGTAAA-3') was used for the SYBR green and TaqMan reactions, resulting in an amplified product of $73 \mathrm{bp}$. The Af2 TaqMan probe was 5'FAM-CGA GCCCAACCTCCCACCCG-3'TAMRA.

For maize, four pairs of primers were designed using the maize $\alpha$-tubulin sequence obtained from GenBank (x73980.1). Primer pair Zmt3 (forward primer: 5'TCCTGCTCGACAATGAGGC-3'; reverse primer: 5'-TTGGGCGCTCAATGTCAA$3^{\prime}$ ) was used for the SYBR green reactions, resulting in an amplified product of $63 \mathrm{bp}$. In addition to the primers designed for this experiment, the primer pair FINCW297/RINCW2-97, designed by Murray et al. (26), were tested in the optimization assays for the TaqMan reactions.

qPCR development and optimization. Two qPCR methods, SYBR green and TaqMan, were developed and validated. All of the qPCR experiments were conducted in an Applied Biosystems ABI PRISM 7000 Sequence Detection System, with 96-well reaction plates and optical adhesive covers or optical caps (Applied Biosystems). Sequence detection primers and TaqMan TAMRA probes were also obtained from Applied Biosystems.

SYBR green optimization. The specificity of each primer and the optimal annealing temperature were determined by gradient PCR with control DNA of Fusarium graminearum and Penicillium spp. because these fungi are commonly found in maize ears. Reactions for optimization were conducted as recommended for Power SYBR Green PCR Master Mix (Applied Biosystems). qPCR reactions were first tested with a profile of $95^{\circ} \mathrm{C}$ for $10 \mathrm{~min}$ and 40 cycles of $95^{\circ} \mathrm{C}$ for $30 \mathrm{~s}, 37^{\circ} \mathrm{C}$ for $30 \mathrm{~s}$, and $72^{\circ} \mathrm{C}$ for 30 s. DNA samples were pure pathogen or host DNA at $10 \mathrm{ng} / \mu \mathrm{l}$ and a mixed sample of $10 \mathrm{ng} / \mu \mathrm{l}$ of pathogen diluted in host DNA at $1 \mathrm{ng} / \mu \mathrm{l}$. Each reaction was prepared in $25 \mu \mathrm{l}$ with $1 \times$ Master Mix, $3 \mu$ l of template, and variable concentrations of forward and reverse primers. Af 2 and $\mathrm{Zmt} 3$ primer concentrations were tested at 200, 75, and $50 \mathrm{nM}$. A dissociation curve was created for each reaction. Temperature profiles were adjusted to reduce the presence of dimer. A two-step profile was tested and reduced times for each step of the cycle were also assessed.

To create standard curves, pathogen DNA was diluted in water at $10,1,0.1$, 0.01 , and $0.001 \mathrm{ng} / \mu \mathrm{l}$. Host DNA was diluted to $100,10,1,0.1,0.01$, and 0.001 $\mathrm{ng} / \mu \mathrm{l}$, and a mixed DNA standard curve was prepared by diluting pathogen DNA at $10,1,0.1,0.01$, and $0.001 \mathrm{ng} / \mu \mathrm{l}$ in host DNA at $1 \mathrm{ng} / \mu \mathrm{l}$. Aliquots were prepared and frozen at $-20^{\circ} \mathrm{C}$, keeping a working dilution at $4^{\circ} \mathrm{C}$. For the efficiency calculation of each primer pair, qPCR was con- 
ducted in $25-\mu$ l reactions and 40 cycles. Efficiency of the reaction was determined by the formula $E=10^{(-1 / \text { slope })}-1$, as recommended by the Applied Biosystems real-time PCR training modules. When using a standard curve with a logarithmic dilution, such as the one used in this study, a $100 \%$ efficient reaction would have a slope of -3.3386 . This efficiency value can be used to evaluate the quality of the primer design for absolute quantification of DNA in a qPCR reaction. Slopes between 90 and $110 \%$ efficiency are generally considered acceptable.

TaqMan optimization. The reactions for optimization were conducted as recommended for the TaqMan Universal PCR Master Mix (Applied Biosystems) and as reported by Valsesia et al. (37). The initial reaction conditions were the optimal SYBR green reaction. As before, a twostep PCR was tested. Primer concentrations were tested individually for the Af2, $\mathrm{Zmt3}$, and INCW2-97 primers at 200, 75, and $50 \mathrm{nM}$, with probes at $200 \mathrm{nM}$. When the appropriate primer concentrations were identified, the probes were tested at 50, $100,150,200$, and $250 \mathrm{nM}$. After probe and primer concentrations were optimized, multiplex reactions were tested using 75 nM Af2 primers, $200 \mathrm{nM}$ Af2 probe, 75 $\mathrm{nM}$ Zmt3 or INCW2-97 primers, and variable Zmt3 or INCW2-97 probe concentrations.

qPCR reproducibility assays. SYBR green reproducibility. DNA was extracted from four samples of ground maize for which aflatoxin concentrations had been previously determined (as described below). For each of the samples, six independent subsamples of approximately 100 mg were extracted in a single 96-well plate.

Optimal conditions (see Results) for the SYBR green reaction were used with one of the extracted samples for each aflatoxin concentration. DNA was diluted 10 -fold to have total DNA concentrations between 1 and $100 \mathrm{ng} / \mu \mathrm{l}$. Each qPCR plate contained eight replicates of each sample and a duplicated standard (pathogen DNA at 0.1 $\mathrm{ng} / \mu \mathrm{l}$ in host DNA at $1 \mathrm{ng} / \mu \mathrm{l})$. There were two wells for each sample, one with Af2 primers and another with $\mathrm{Zmt} 3$ primers. The qPCR experiment was conducted four times. $\mathrm{Ct}$ values for each plate were corrected based on the standard sample by adding a dCT, where $\mathrm{dCT}=\mathrm{CT}_{\text {st }}$ (value at which the standard curve is 0.1 for pathogen or 1 for host) $-\mathrm{Ct}_{\mathrm{pl}}$ (average $\mathrm{CT}$ on each plate for the standard sample) (37). Using the standard curves obtained previously from the mixed DNA samples, the corrected $\mathrm{CT}$ value was transformed into DNA concentration. A ratio of pathogen to host DNA $(\mathrm{p} / \mathrm{h})$ was obtained by dividing the pathogen DNA by the host DNA concentrations.

For statistical analysis, the $\mathrm{p} / \mathrm{h}$ ratios were $\log$ transformed and the following mixed model was run on JMP 7 (SAS Institute Inc, Cary, NC): $\log \mathrm{p} / \mathrm{h}=\mathrm{P}_{\mathrm{i}}+\mathrm{B}_{\mathrm{k}[\mathrm{i}]}+$ $C_{j}$, where $P_{i}=$ the random effect of each plate, $\mathrm{B}_{\mathrm{k}[\mathrm{i}]}=$ the random effect of replicate within plate, and $C_{j}=$ the fixed effect of sample.

TaqMan reproducibility. Approximately $100 \mathrm{mg}$ (estimated by volume) of infected ground kernels with four concentrations of aflatoxin contamination (including zero) were placed in three independent plates. DNA extraction was performed using the cetyltrimethylammonium bromide (CTAB) method indicated below and diluted 1:10 in water prior to use. In the qPCR reaction, each plate contained a set of mixed standard curves in duplicate with concentrations of A. flavus DNA at 10, 1, 0.1, 0.01, and $0.001 \mathrm{ng} / \mu \mathrm{l}$ diluted in maize DNA at 1 $\mathrm{ng} / \mu \mathrm{l}$. Three replicates of the qPCR procedure (qPCR plates) were conducted for each DNA extraction plate. Concentrations of pathogen DNA for each sample were estimated using the ABI Prism 7000 SDS Software (version 1.0; Applied Biosystems).

Because a multiplex reaction to estimate the amount of host and pathogen DNA in a single tube was not possible with the primers and probes tested in this study, an infection coefficient (IC) was calculated by obtaining the ratio of DNA estimated by qPCR to the amount of DNA estimated by PICO green (pathogen/total DNA). These values were $\log$ transformed prior to analysis. Data analysis was carried out in JMP 7 (SAS Institute Inc.) using the following model: $\log \mathrm{IC}=\gamma_{\mathrm{i}}+\tau_{\mathrm{j}[\mathrm{i}]}+\Gamma_{\mathrm{k}}+$ $\gamma \Gamma_{\mathrm{ik}}$, where $\gamma_{\mathrm{i}}$ was the random effect of DNA plate (or extraction), $\tau_{\mathrm{j}[\mathrm{i}]}$ was the random effect of technical replicate or qPCR plate within DNA plate, $\Gamma_{\mathrm{k}}$ was the fixed effect of each maize line, and $\gamma \Gamma_{i k}$ was the random interaction of the DNA extraction by maize sample.

ICs in 20 hybrids. The experiment was set up in the field in a randomized complete block design with four blocks. Samples from each of the four biological replicates were placed in a 96-well plate three times for three independent DNA extractions. Each DNA plate was qPCR analyzed with three technical replicates. The qPCR settings and determination of the IC were as indicated for the optimal TaqMan reaction. ICs were log transformed. Data analysis was carried out in JMP 7 (SAS Institute Inc.) using the following mixed effects model: $\log \mathrm{IC}=\beta_{\mathrm{i}}+\gamma_{\mathrm{j}}+\omega_{\mathrm{k}[\mathrm{jl}}+\beta \gamma_{\mathrm{ij}}$ $+\Gamma_{1}+\beta \Gamma_{\mathrm{il}}+\gamma \Gamma_{\mathrm{il}}+\Gamma \omega_{\mathrm{k}[\mathrm{j}]}+\beta \omega_{\mathrm{k}[\mathrm{j}]}+\beta \gamma \Gamma_{\mathrm{ijl}}$, where $\beta_{i}$ was the random effect of biological replicate, $\gamma_{j}$ was the random effect of DNA extraction plate, $\omega_{\mathrm{k}[\mathrm{j}]}$ was the random effect of technical replicate (qPCR plate within DNA extraction plate), $\beta \gamma_{i j}$ was the random interaction of biological replicate by DNA extraction plate, $\Gamma_{1}$ was the fixed effect of maize hybrid, $\beta \Gamma_{\text {il }}$ and $\gamma \Gamma_{\text {il }}$ were the random interactions of hybrid by biological replicate and DNA extraction plate, $\Gamma \omega_{\mathrm{k}[\mathrm{j}]}$ and $\beta \omega_{\mathrm{k}[\mathrm{j}]}$ were the random interactions of maize hybrid and biological replicate by technical replicate within DNA extraction plate, and $\beta \gamma \Gamma_{\mathrm{ijl}}$ was the random three-way interaction of biological replicate by DNA extraction and by maize hybrid.

Aflatoxin concentrations were obtained using the VICAM AflaTest (Watertown, MA) from $50 \mathrm{~g}$ of the same samples used for qPCR. For the analysis of variance (ANOVA), aflatoxin concentrations were $\log$ transformed.

ICs in 18 diverse inbreds. This experiment was established in the field in a randomized complete block design with three blocks. DNA was extracted from ground kernels from each line once. qPCR was conducted as indicated for the optimal TaqMan reaction and replicated three times. ICs were log transformed. Data analysis was carried out in JMP 7 (SAS Institute Inc.) using the following mixed effects model: $\log \mathrm{IC}=\beta_{\mathrm{i}}+\omega_{\mathrm{k}}+\Gamma_{\mathrm{l}}$, where $\beta_{\mathrm{i}}$ was the random effect of biological replicate, $\omega_{\mathrm{k}}$ was the random effect of technical replicate, and $\Gamma_{1}$ was the fixed effect of maize inbred.

Plant materials and fungal inoculation. For the development of the qPCR and tests of its reproducibility, four samples of ground maize kernels with aflatoxin contamination at $0,60,630$, and 2,320 ng/g were used (Table 1). For all inoculations, A. flavus isolate NRRL 3357 was seeded onto $50 \mathrm{~g}$ of sterile maize cob grits with $100 \mathrm{ml}$ of $\mathrm{H}_{2} \mathrm{O}$ and incubated at $28^{\circ} \mathrm{C}$ for 3 weeks. Before adjusting the concentration of the inoculum, the suspension was filtered through four layers of cheesecloth. The side-needle technique was used, in which $3.4 \mathrm{ml}$ of a suspension of $3 \times 10^{8}$

Table 1. Reproducibility assays for the SYBR green and TaqMan reactions assays for Aspergillus flavus biomass estimated as pathogen/host DNA ratio ( $\mathrm{p} / \mathrm{h}$ ) or infection coefficients (ICs) on aflatoxincontaminated kernel samples

\begin{tabular}{|c|c|c|c|c|c|}
\hline \multirow[b]{2}{*}{ Sample } & \multirow[b]{2}{*}{ Aflatoxin (ng/g) } & \multicolumn{2}{|c|}{ SYBR green assay } & \multicolumn{2}{|c|}{ TaqMan assay } \\
\hline & & $\log \mathbf{p} / \mathbf{h}$ & $\mathrm{p} / \mathrm{h}(\%)$ & $\log \mathrm{IC}$ & IC \\
\hline High & 2,320 & $-1.35 \mathrm{a}^{\mathrm{z}}$ & 26.0 & $4.70 \mathrm{a}$ & 109.4 \\
\hline Medium & 630 & $-2.70 \mathrm{~b}$ & 6.7 & $2.50 \mathrm{~b}$ & 11.1 \\
\hline Low & 60 & $-5.40 \mathrm{c}$ & 0.5 & $1.21 \mathrm{c}$ & 2.4 \\
\hline Control & 0 & $-8.72 \mathrm{~d}$ & 0.0 & $0.03 \mathrm{~d}$ & 0 \\
\hline
\end{tabular}

${ }^{\mathrm{z}}$ Levels not connected by same letter are significantly different as determined by Tukey test $(\alpha=$ $0.05)$. 
conidia/ml was injected underneath the husk into the side of the top ear 7 days after $50 \%$ of the silks had emerged on each row (44).

In order to study the correlation of aflatoxin concentration and A. flavus colonization, two sets of maize lines were inoculated. First, a set of 19 hybrids developed at the USDA-ARS Corn Host Plant Resistance Research Unit breeding program and a commercial hybrid, Pioneer Brand 3394, were field inoculated as explained above at the Mississippi State field station. This experiment was planted in a completely randomized block design with four replicates. Second, 18 diverse inbreds $(12,21)$ were planted in a completely randomized block design with three replicates. Each line was planted in 4-m single-row plots spaced $0.97 \mathrm{~m}$ apart. Standard production practices for the region were followed (43). At harvest, the top ears of each plant in a row were dried at $38^{\circ} \mathrm{C}$ for 7 days. Kernels from each row were ground with a Romer mill (Union, MO) and a subsample of $50 \mathrm{~g}$ was used for aflatoxin measurement using the VICAM AflaTest.

DNA extraction. For the initial primer specificity tests and preparation of standard curves, A. flavus stock cultures (kept in $50 \%$ glycerol at $-80^{\circ} \mathrm{C}$ ) were streaked on potato dextrose agar plates (PDA; BD, Sparks, MD). Forty-eight hours later, a single colony was selected and plated on a PDA plate. Abundant conidia were harvested 3 to 5 days later by rinsing the plate
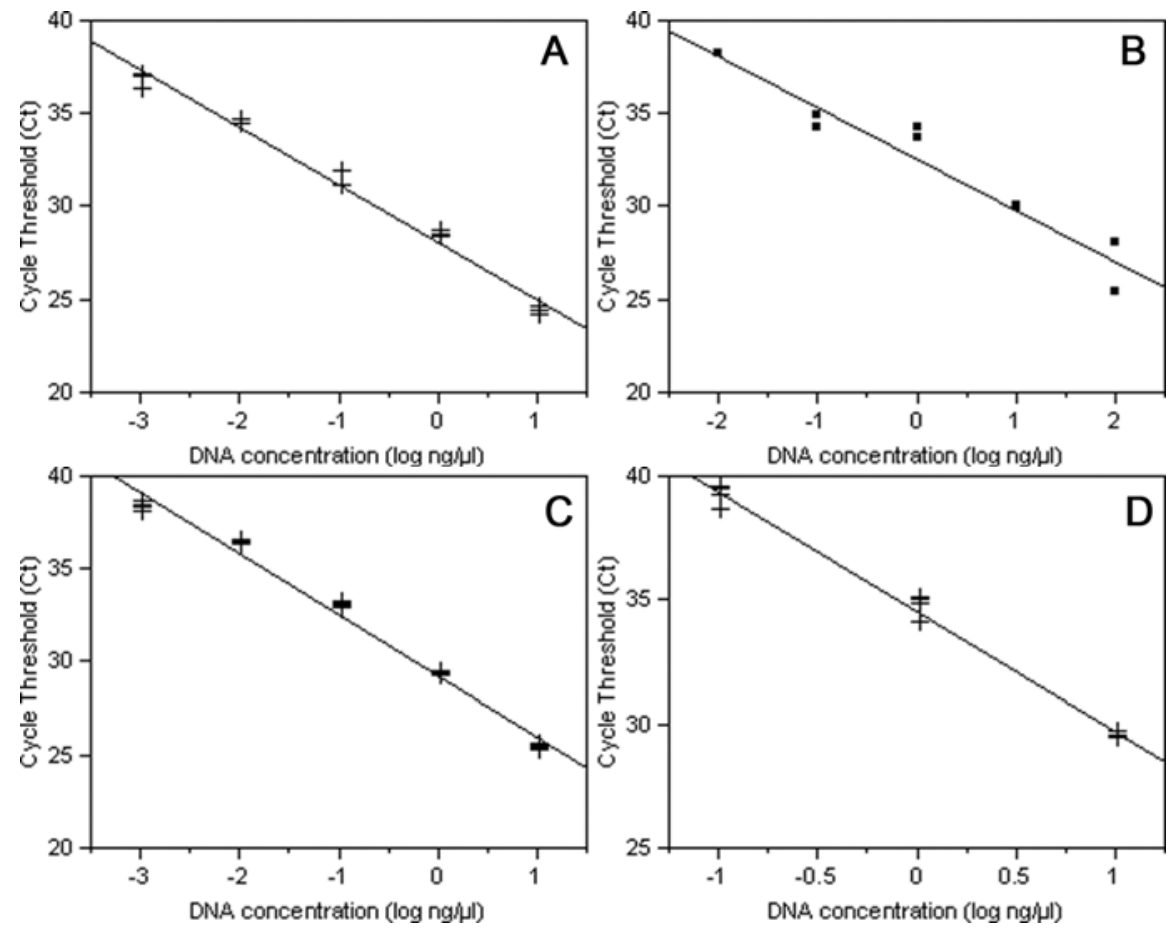

Fig. 1. Standard curves. A, SYBR green reaction with Aspergillus flavus DNA and Af2 primers, efficiency: $110 ; R^{2}=0.98 ; y=28.12-3.08(x),(n=3)$. B, SYBR green reaction with maize DNA and Zmt3 primers, efficiency: $130 ; R^{2}=0.93 ; y=32.57-2.75(x),(n=2)$. C, TaqMan reaction with $A$. flavus DNA and Af2 primers and probe, efficiency 101; $R^{2}=0.99 ; y=29.25-3.29(x)(n=4)$. D, TaqMan reaction with mixed DNA and Af2 primers and probe efficiency: $61.5 ; R^{2}=0.99 ; y=34.55-$ $4.81(x),(n=3)$.
Prior to DNA extraction, A. flavusinfected dry maize kernel samples (ground and prepared for aflatoxin determination) were kept at $4^{\circ} \mathrm{C}$ until processed. Approximately $100 \mathrm{mg}$ of infected ground kernels were placed in 1.2-ml polypropylene Costar cluster tubes (Corning Inc., Corning, NY) that contained stainless steel $5 / 32^{\prime \prime}$ grinding balls (OPS Diagnostics, Lebanon, NJ) in 96-well racks. Plates were homogenized in GENO/GRINDER 2000 (SPEX CertiPrep Inc., Metuchen, NJ) at 550 strokes/min for $40 \mathrm{~s}$. Plates were transferred to liquid nitrogen and then homogenized again. CTAB extraction buffer (500 $\mu \mathrm{l}$ per sample) was added and plates were incubated at $60^{\circ} \mathrm{C}$ for $5 \mathrm{~min}$. Samples were mixed by inverting the plates 70 times and then incubated at $60^{\circ} \mathrm{C}$ for $10 \mathrm{~min}$. Cloroform:isoamyl alcohol (24:1) was then added in two rounds for a total of $400 \mu \mathrm{l}$ and the plates were inverted 70 times. Plates were then centrifuged at $3,000 \times g$ for $12 \mathrm{~min}$ at $4^{\circ} \mathrm{C}$. The supernatant was transferred to clean tubes and $300 \mu$ of isopropanol $\left(-20^{\circ} \mathrm{C}\right)$ was added. The plates were mixed by inverting 15 times and then chilled for a minimum of $1 \mathrm{~h}$ at $-20^{\circ} \mathrm{C}$. Plates were then centrifuged at $1,700 \times g$ for $15 \mathrm{~min}$ at $4^{\circ} \mathrm{C}$. Next, $300 \mu \mathrm{l}$ of 70 and then $90 \%$ ethanol was added to the samples and centrifuged at $5,890 \times g$. The pellets were dried and resuspended in 100 $\mu \mathrm{l}$ of nanopure $\mathrm{H}_{2} \mathrm{O}$. DNA was quantified using Picogreen (Invitrogen Corp., Carlsbad, CA) in a SPECTRAFLUOR PLUS fluorometer (Tecan US Inc., Research Triangle Park, NC) as indicated by the manufacturer's protocols.

\section{RESULTS}

qPCR optimal conditions. SYBR green reaction. Optimal primer concentrations were 200 and $75 \mathrm{nM}$ for the Af2 forward and reverse primers, respectively. Power SYBR green PCR Master Mix (Applied Biosystems) was used at $1 \times$ concentration with $3 \mu \mathrm{l}$ of sample template (approximately 1 to $100 \mathrm{ng} / \mu \mathrm{l}$ ) in $25-\mu \mathrm{l}$ reactions. The most successful PCR conditions were $95^{\circ} \mathrm{C}$ for $10 \mathrm{~min}$ and 40 cycles of $95^{\circ} \mathrm{C}$ for $30 \mathrm{~s}, 59^{\circ} \mathrm{C}$ for $30 \mathrm{~s}$, and $72^{\circ} \mathrm{C}$ for $30 \mathrm{~s}$. For the SYBR green reactions, maize primers were used to estimate the amount of host DNA present in the sample in separate reactions under the same conditions but with $\mathrm{Zmt} 3$ primers at concentrations of 50 nM. There was a consistent dimer formation of the $\mathrm{Zmt} 3$ primers in the presence of A. flavus DNA.

SYBR green standard curves. Af2 primers had a good linear relation, with $111 \%$ efficiency within the range of 10 to 0.001 $\mathrm{ng} / \mu \mathrm{l}$ (Fig. 1A). The efficiency of these same primers was $98 \%$ in the pathogenonly DNA sample if considering only DNA concentrations from 10 to $0.01 \mathrm{ng} / \mu \mathrm{l}$. In the standard curves from mixed DNA samples, amplification was detected only from 10 to $0.01 \mathrm{ng} / \mu \mathrm{l}$ and the efficiency of the 
reaction was $76 \%$. This was the curve used for the SYBR reproducibility assays with regression function: $y=31.34-4.04(x)$ and $R^{2}=0.97$. Using the Af2 primers, there was no detectable amplification of maize DNA but a small dimer band was visible at the lowest maize DNA concentrations. Dissociation curves confirmed the occurrence of nonspecific amplification.

For maize primers $\mathrm{Zmt} 3$, there was a strong dimer band visible on agarose gels when amplification was conducted in the presence of A. flavus DNA (not shown). The reaction efficiency of the PCR from 100 to $0.01 \mathrm{ng} / \mu \mathrm{l}$ was $130 \%$ (Fig. 1B). This value was outside the accepted range $(100 \pm 10 \%)$. In spite of this, for the mixture of A. flavus and maize DNA, Ct values for the mixed curve were almost exactly those of the host standard curve at $1 \mathrm{ng} / \mu \mathrm{l}$, supporting the validity of the assay. At the maize DNA concentrations expected to be in samples for quantification (between 1 and $100 \mathrm{ng} / \mu \mathrm{l})$, we consider the use of these primers to be acceptable. For the SYBR reproducibility assays, the maize standard curve was used only in the range of 100 to $1 \mathrm{ng} / \mu \mathrm{l}$, which had an efficiency of $101 \%$ (the regression line was $y=33.61$ $-3.29[x])$.

TaqMan reaction. Optimal primer and probe concentrations were $75 \mathrm{nM}$ for Af2 forward and reverse primers and $200 \mathrm{nM}$ for the Af2 probe. As before, $3 \mu \mathrm{l}$ of DNA template was used along with $1 \times$ PERFECTA qPCR SUPER MIX, UNG, ROX (Quanta Biosciences, Inc. Gaithersburg, MD) or TaqMan Universal PCR Master Mix (Applied Biosystems). Reactions (25$\mu \mathrm{l})$ were carried out with a profile of $2 \mathrm{~min}$ at $50^{\circ} \mathrm{C} ; 10 \mathrm{~min}$ at $95^{\circ} \mathrm{C}$; and 40 cycles of 95,59 , and $72^{\circ} \mathrm{C}$ for $30 \mathrm{~s}$ each. The Zmt 3 primers and probe produced nonspecific amplification when used in tandem and, thus, were not used for the TaqMan reactions.

TaqMan standard curves. The standard curves indicated that the Af2 primers and probe worked very well; a linear relation was found with an efficiency of $101.5 \%$ and $R^{2}=0.99$ (Fig. 1C). This reaction was repeated twice with four replicates each and similar results were obtained. When using mixed standard curves of A. flavus DNA diluted in maize DNA at $1 \mathrm{ng} / \mu \mathrm{l}$, the efficiency of the Af2 detector was reduced to $61.4 \%\left(R^{2}=0.99\right)$ and the detection only occurred with $A$. flavus DNA at 10 to $0.1 \mathrm{ng} / \mu \mathrm{l}$ (Fig. 1D). Fungal biomass was estimated using the curve of A. flavus diluted in maize DNA at $1 \mathrm{ng} / \mu \mathrm{l}$ that had the following regression line: $y=34.55-$ 4.81(x).

The standard curves using the $\mathrm{Zmt} 3$ primers and probe for the mixed standard curves clearly showed nonspecific interaction of the Zmt3 detector with A. flavus DNA, and they were not used for further analysis. Other detectors were also tried but the INCW2-97 primers and probe used for maize (26) did not work in tandem reactions with the Af2 primers and probe.

Reproducibility assay. SYBR green reproducibility. There were no significant differences for the total DNA concentration of the samples with aflatoxin concentration at 2,320,630,60, and $0 \mathrm{ng} / \mathrm{g}(P=$ 0.517 ; mean $128.1 \mathrm{ng} / \mu \mathrm{l}$, data not shown). In the qPCR experiments, technical replicates were a significant source of random variance whereas the replicates of the samples within a plate were not a significant source of variation. Significant differences $(P<0.0001)$ for the $\mathrm{p} / \mathrm{h}$ ratio were found among samples with different concentrations of aflatoxin contamination (Table 1; Fig. 2). The correlation between $\mathrm{p} / \mathrm{h}$ DNA ratio and aflatoxin concentration was 0.98 in 95 samples $(P<0.0001)$.

TaqMan reproducibility. Multiple DNA extraction plates were included in this experiment. The ANOVA showed that DNA extractions did not contribute significantly to the random variance of the experiment. However, technical replicates (qPCR plate), similarly to the results in the SYBR green reaction, were a significant source of random variance (51 and 53\% of the total variance estimates, respectively). Significant differences $(P<0.0001)$ were found for the fixed effect of maize sample with different aflatoxin concentrations (Table 1; Fig. 2B). The correlation between IC and aflatoxin concentration was 0.81 in 36 samples $(P<0.0001)$.

Fungal infection and aflatoxin conmaize hybrids tested showed a wide range of responses to inoculation with A. flavus, with aflatoxin measurements ranging from 19 to $1188 \mathrm{ng} / \mathrm{g}$. Significant differences $(P$ $<0.0001$ ) were found for fungal biomass estimated as IC for the fixed effect of hybrid (Table 2). Differences among hybrids were also significant $(P<0.0001)$ for aflatoxin concentration levels (Table 3 ). DNA extraction was not a significant source of random variation. However, technical repcentration in 20 maize hybrids. The

licates within DNA extraction plate and the interaction of hybrid-biological replicate were significant sources of random variation (Table 2). Pearson correlation between the IC determined by qPCR and aflatoxin concentration was $0.85(P<0.0001, n=$ 20; Fig. 3A).

Fungal infection and aflatoxin concentration in 18 diverse inbreds. Significant differences were found among the diverse inbred maize lines $(P<0.0001)$ that showed a wide range of aflatoxin concentrations (94 to $22,734 \mathrm{ppb}$; Table 4). The ICs were also significantly different $(P$ $<0.0001$ ) but the range of values was smaller than for aflatoxin. Pearson correlation between the IC determined by qPCR and aflatoxin concentration was $0.81(P<$ $0.0001, n=18$; Fig. 3B).

\section{DISCUSSION}

We have demonstrated that qPCR can be used to reproducibly quantify A. flavus infection in maize kernels. Although the SYBR green technique was found to be acceptable, we favor the TaqMan method because of the higher levels of efficiency and sensitivity obtained during the validation experiments. For this method, DNA is extracted from $100 \mathrm{mg}$ of infected tissue. Optimized PCR reactions $(25 \mu \mathrm{l})$ contained $75 \mathrm{nM}$ Af2 forward and reverse primers, $200 \mathrm{nM}$ Af2 probe, and $1 \times$ PerfeCTa qPCR Super Mix, UNG, ROX (Quanta Biosystems) or TaqMan Universal PCR Master Mix (Applied Biosystems). DNA template ( $3 \mu \mathrm{l})$ was added to each reaction. DNA concentration of each sample was determined using Picogreen and all the samples were diluted equally in order to have a maximum DNA concentration of 100 $\mathrm{ng} / \mu \mathrm{l}$. We did not adjust the template DNA concentration for each sample before the qPCR reaction. Each qPCR plate contained a set of mixed standard curves in duplicate with concentrations of $A$. flavus DNA at $10,1,0.1,0.01$, and $0.001 \mathrm{ng} / \mu \mathrm{l}$ diluted in maize DNA at $1 \mathrm{ng} / \mu \mathrm{l}$. The thermal profile
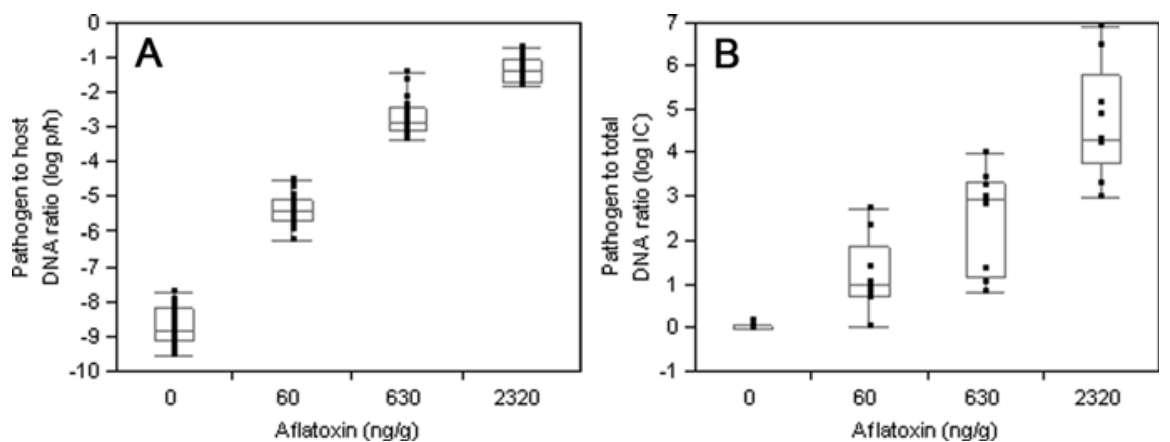

Fig. 2. Reproducibility assays. A, SYBR green reaction for three samples of ground maize kernels infected samples with known concentrations of aflatoxin contamination and a control. A ratio of the pathogen to host DNA $(\mathrm{p} / \mathrm{h})$ was obtained. Significant differences were found among treatments $(P<$ $0.0001)$. The correlation between $\mathrm{p} / \mathrm{h}$ and aflatoxin concentration was $0.98(P<0.0001, n=95)$. B, TaqMan reaction for the same four samples. An infection coefficient (IC) was calculated by dividing the amount of DNA estimated with quantitative real-time polymerase chain reaction by the amount estimated with PicoGreen (pathogen/total DNA). Significant differences were found for the category effect $(P<0.0001)$. The correlation between IC and aflatoxin ppb was $0.81(P<0.0001, n=36)$. 
was $2 \mathrm{~min}$ at $50^{\circ} \mathrm{C} ; 10 \mathrm{~min}$ at $95^{\circ} \mathrm{C}$; and 40 cycles of 95,59 , and $72^{\circ} \mathrm{C}$ for $30 \mathrm{~s}$ each. Three replicates of the qPCR procedure (qPCR plates) were conducted for each sample. Concentrations of pathogen DNA for each sample were estimated using the ABI Prism 7000 SDS Software (version 1.0; Applied Biosystems). ICs were calculated by dividing the amount of pathogen DNA by the total DNA for each sample.

We have shown that the levels of fungal biomass were strongly correlated with aflatoxin accumulation in two sets of fieldinoculated maize lines representing a broad range of genetic diversity. This finding indicates that fungal biomass estimated by qPCR could be used to infer the concentration of aflatoxin and that aflatoxin concentration should reflect levels of fungal biomass. It is important to acknowledge that this conclusion is based on a limited sample of maize germplasm and is not necessarily applicable to all maize lines under all environmental conditions. Other studies have found that maize genotype could affect the accumulation of aflatoxin as discussed below. In future, it would be informative to apply our qPCR technique to a larger maize population to clarify the effect of maize genotypes on the production of aflatoxins by A. flavus.

The cost of qPCR in a well-equipped molecular biology laboratory is lower than immunocapture aflatoxin determination (e.g., VICAM AflaTest) but more expensive than other plate-based ELISA methods. Our technique is especially valuable for pathology and breeding programs in which A. flavus infection levels are under study. The method may also prove useful for detection and quantification in soil samples. The use of this technique with other Aspergillus spp. should be tested prior to use.

qPCR is now commonly used in plant pathology as a detection method; for example, to identify Phytophthora spp. in forests (31). It has also been suggested as a method for the assessment of host resistance to Plasmopara viticola in grapevine (37). qPCR has also been used successfully to monitor the progression of aspergillosis, caused by A. fumigatus, in human serum and mouse $(1,7)$. A previous study reported on the quantification of A. flavus in food by qPCR, using primers to the nor1 gene in the aflatoxin-producing pathway (23). For our study, we designed the $A$.

Table 2. $F$ tests for the fixed and random effects on the infection levels estimated by quantitative realtime polymerase chain reaction of 20 hybrids field inoculated with Aspergillus flavus

\begin{tabular}{lrcr}
\hline Source & df & $\boldsymbol{F}$ statistic & $\boldsymbol{P}$ \\
\hline Biological replicate (BR) & 3 & 0.8919 & 0.4808 \\
DNA extraction (DE) & 2 & 1.5053 & 0.2777 \\
Technical replicate (TR) within DE & 6 & 5.9038 & 0.0013 \\
BR $\times$ DE & 6 & 1.9561 & 0.0919 \\
Hybrid & 19 & 7.7169 & $<0.0001$ \\
Hybrid $\times$ BR & 57 & 2.0504 & 0.0006 \\
Hybrid $\times$ DE & 38 & 0.6776 & 0.9151 \\
Hybrid $\times$ TR[DE] & 114 & 1.1987 & 0.1100 \\
BR $\times$ TR[DE] & 18 & 7.0273 & $<0.0001$ \\
BR $\times$ DE $\times$ hybrid & 114 & 5.7637 & $<0.0001$ \\
\hline
\end{tabular}

flavus primers within the ITS1. This region is located between the $18 \mathrm{~S}$ and $5.8 \mathrm{~S}$ ribosomal RNA genes and it is estimated that there are approximately 100 copies per genome (16). For this reason, we obtained high sensitivity demonstrated by the detection of $1 \mathrm{pg}$ of $A$. flavus DNA in the standard curves. Cruz and Buttner (9) used primers designed in the ribosomal DNA genes and the ITS2 to successfully differentiate A. flavus grown in culture from another 36 fungal species grown on petri plates as well as human and bacterial DNA. Unfortunately, by the time our study was completed, we were not aware of their results; therefore, we did not use their primers in our study. In our article, we demonstrated the value of the method by identifying maize hybrids that allow significantly lower levels of A. flavus biomass estimated as an IC. The use of this method and primers provide a tool for the detailed study of the infection process and its relationship with aflatoxin accumulation. For example, the early rates of colonization could be studied in different maize lines by dissecting infected tissue and analyzing by qPCR. Along this line, we are successfully using the TaqMan technique to map resistance QTL affecting the early infection process in developing kernels and silk tissue.

Several pairs of $Z$. mays-specific primers failed to produce reliable results and, thus, we were unable to create a multiplex TaqMan reaction in which both host and pathogen DNA could be quantified from the same sample. The maize $\alpha$-tubulin genes designed for this study had problems of dimer formation but performed acceptably for the SYBR green reaction. However, for the TaqMan reaction, the PCR amplification was nonspecific, perhaps due to the addition of the probes. Murray et al. (26) reported on a qPCR technique used to

Table 3. Differences between Aspergillus flavus biomass infection coefficient (IC) determined by quantitative real-time polymerase chain reaction and aflatoxin concentration for maize hybrids inoculated in the field ${ }^{\mathrm{z}}$

\begin{tabular}{|c|c|c|c|c|}
\hline \multirow[b]{2}{*}{ Pedigree/Line } & \multicolumn{2}{|c|}{ A. flavus } & \multicolumn{2}{|c|}{ Aflatoxin } \\
\hline & $\log (\mathrm{IC}+1)$ & IC & $\log (\mathbf{n g} / \mathbf{g}+1)$ & $\mathbf{n g} / \mathbf{g}$ \\
\hline P3394 & $3.67 \mathrm{a}$ & 38.1 & $7.08 \mathrm{a}$ & 1,188 \\
\hline (CH05015:n12-43-1-B-B)-3-2 × T173 & $3.47 \mathrm{ab}$ & 31.2 & $6.75 \mathrm{ab}$ & 850 \\
\hline Mp97:154 × T173 & $2.98 \mathrm{abc}$ & 18.7 & $6.70 \mathrm{ab}$ & 812 \\
\hline GA209 $\times$ SC212M & $2.71 \mathrm{abcd}$ & 14.0 & $6.83 \mathrm{ab}$ & 922 \\
\hline$(\mathrm{Mp} 313 \mathrm{E} \times$ Va35 Fam 58)-2-3-1-1-2-2 x T173 & 2.45 abcde & 10.6 & 5.46 abcde & 235 \\
\hline CML $322 \times$ T173 & 2.31 abcde & 9.1 & $6.56 \mathrm{abc}$ & 705 \\
\hline CML326 × T173 & 2.31 abcde & 9.0 & $6.39 \mathrm{abcd}$ & 597 \\
\hline $\mathrm{Mp} 420 \times \mathrm{T} 173$ & 2.22 abcde & 8.2 & 6.02 abcde & 412 \\
\hline CML342 × T173 & 2.15 abcde & 7.6 & 6.26 abcd & 522 \\
\hline (MBR-ET WHITE F2-112-1-1 × B-B-\#-B-\#)-1-2 × T173 & 1.96 bcde & 6.1 & $6.53 \mathrm{abc}$ & 687 \\
\hline Mp97:161 × T173 & $1.56 \mathrm{cde}$ & 3.7 & 5.59 abcde & 266 \\
\hline CML247 × T173 & $1.43 \mathrm{cde}$ & 3.2 & $4.39 \mathrm{cdef}$ & 79 \\
\hline Mp92:673 × T173 & $1.34 \mathrm{cde}$ & 2.8 & $4.30 \mathrm{def}$ & 73 \\
\hline (Mp $715 \times$ Va35)-1-3-4-2-1 × T173 & $1.18 \mathrm{de}$ & 2.3 & 5.10 abcdef & 163 \\
\hline CML348 $\times$ T173 & $1.18 \mathrm{de}$ & 2.3 & 5.05 abcdef & 156 \\
\hline Mo18W × Mp313E & $1.09 \mathrm{de}$ & 2.0 & 5.06 abcdef & 156 \\
\hline Mp494 × Mp92:673 & $1.03 \mathrm{de}$ & 1.8 & $3.22 \mathrm{f}$ & 24 \\
\hline (MBR-ET WHITE F2-112-1-1 × B-B-\#-B-\#)-1-1 × T173 & $1.03 \mathrm{de}$ & 1.8 & 4.77 bcdef & 117 \\
\hline Mp313E × Mp715 & $0.92 \mathrm{e}$ & 1.5 & $2.99 \mathrm{f}$ & 19 \\
\hline Mp494× Mp715 & $0.85 \mathrm{e}$ & 1.3 & $3.89 \mathrm{ef}$ & 48 \\
\hline
\end{tabular}

${ }^{\mathrm{z}}$ Levels not connected by same letter are significantly different as determined by Tukey test $(\alpha=0.05)$. 
estimate maize endogenous DNA degradation using maize-specific primers and TaqMan probes in the cell wall invertase gene (INCW primers; 26). These primers and probe were quite specific when using pure maize DNA from the inbred line B73 but did not work when used in tandem (host plus pathogen) PCR reactions. Results not shown from the optimization assays indicated that the addition of maize DNA at higher concentrations (100 instead of $1 \mathrm{ng} / \mu \mathrm{l}$ ) to the A. flavus standard curve had the effect of delaying the reaction instead of affecting the efficiency when using the Af2 primers and probe. This indicates that variable amounts of maize DNA do not affect the accuracy of the quantification. Adding the INCW primers, in contrast, had a negative effect on the efficiency of the Af2 detector, and this would make for an inaccurate quantification. Possible causes for this are the amplification of nontarget regions or primer interactions with other nucleic acids that compete with the amplification of the specific product. In addition, $A$. flavus isolates have been reported to have PCR inhibitors (9). In the end, it was concluded that the most accurate quantification of fungal biomass in maize lines with diverse genetic backgrounds would be achieved by using only the A. flavus-specific primers and probe with a standard curve of pathogen DNA diluted in maize DNA at $1 \mathrm{ng} / \mu \mathrm{l}$ in each plate.

Through a series of reproducibility assays and an experiment involving multiple biological and technical replicates, we were able to determine the most important effects for biomass determination using qPCR. We found that DNA extraction and its interaction with hybrid lines, as well as replicates within a plate, did not add significant levels of variance to our experiments. These results suggested that, with our methods, DNA extraction or the number of replicates within a plate does not affect the outcome of the biomass estimation. On the other hand, technical replicates are a source of variation; therefore, multiple qPCR plates must be run in order to obtain accurate results. Significant sources of random variance were found for all the interactions involving biological replicates. Aflatoxin concentrations in field experiments are highly variable, and our results suggest that this variation is due to how extensively maize kernels are colonized as opposed to how much toxin is produced for a given degree of colonization.

A strong correlation between A. flavus biomass and aflatoxin accumulation was found among the maize genotypes tested in this experiment. In another study, conducted using a GFP-producing isolate, a similar correlation (0.85) was found between fluorescence and aflatoxin concentration in cottonseed (29). A good correspondence in ranks between visual GUS ratings and aflatoxin concentration was also reported from five maize lines inoculated with a GUS-transformed isolate (5). These results are not consistent with the idea that pathogen load and aflatoxin accumulation are distinct traits in maize, at least with the germplasm and conditions used here. However, it is important to point out that there is evidence of conditions that allow fungal growth with low aflatoxin contamination. Using a GUS-expressing $A$. flavus strain, Brown et al. (4) showed that one African aflatoxin resistant inbred maize line (no. 1368) allowed high levels of infection while two inbred maize lines (nos. 1188 and 15) with high aflatoxin contents supported low levels of infection. The set of inbreds tested was selected to represent a relatively broad genetic diversity. Our panel of hybrids represented a
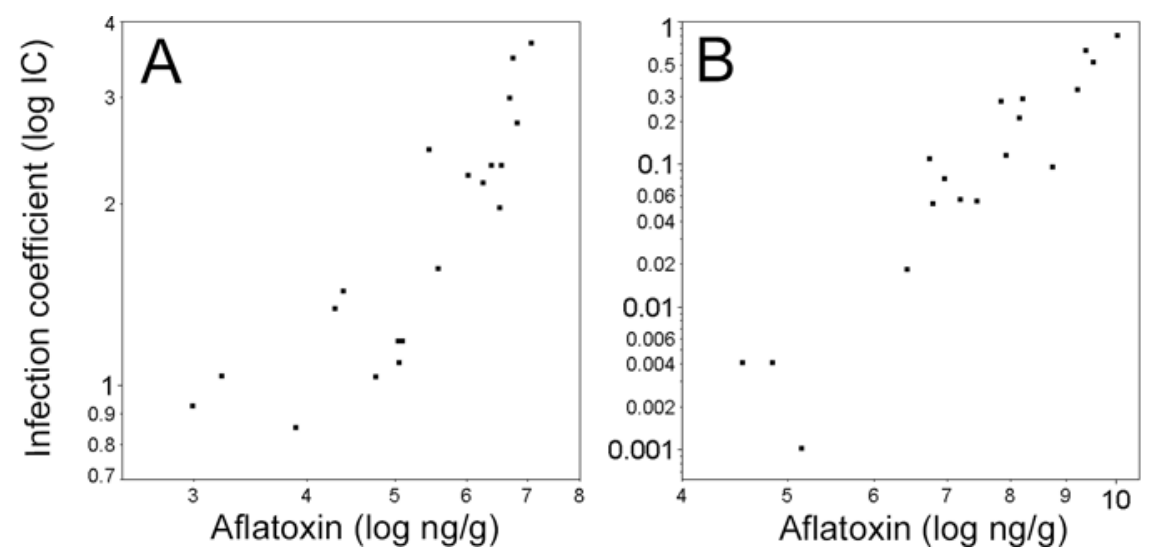

Fig. 3. A, Correlation $(0.85 ; P<0.0001)$ between fungal biomass estimated as infection coefficient (IC) and aflatoxin concentration for 20 field-inoculated maize hybrids. The field experiment had four biological replicates. IC was estimated by TaqMan quantitative real-time polymerase chain reaction (qPCR) from three independent DNA extractions, and each DNA sample was analyzed three times (technical replicates). IC was calculated by dividing the amount of A. flavus DNA obtained from qPCR by the total DNA present in the sample. B, Correlation $(0.81 ; P<0.0001)$ between IC and aflatoxin average levels for a set of diverse maize inbreds $(n=18)$. The field experiment had three replicates and the qPCR experiment was conducted three times (technical replicates). IC was calculated as indicated for the TaqMan reproducibility assay.

Table 4. Differences between Aspergillus flavus infection coefficient (IC) determined by quantitative real-time polymerase chain reaction and aflatoxin concentration for a panel of diverse maize inbreds inoculated in the field

\begin{tabular}{lccccc}
\hline & \multicolumn{2}{c}{ A. flavus } & & \multicolumn{2}{c}{ Aflatoxin } \\
\cline { 2 - 3 } \cline { 5 - 6 } Pedigree/Line & $\mathbf{l o g}(\mathbf{I C}+\mathbf{1})$ & $\mathbf{I C}$ & & $\mathbf{l o g}(\mathbf{n g} / \mathbf{g}+\mathbf{1})$ & $\mathbf{n g} / \mathbf{g}$ \\
\hline CML103 & $0.78 \mathrm{a}^{\mathrm{z}}$ & 1.18 & & $10.03 \mathrm{a}$ & 22,735 \\
Mo17 & $0.62 \mathrm{ab}$ & 0.85 & & $9.39 \mathrm{ab}$ & 11,982 \\
B73 & $0.51 \mathrm{abc}$ & 0.67 & & $9.54 \mathrm{ab}$ & 13,917 \\
B97 & $0.33 \mathrm{bcd}$ & 0.39 & & $9.22 \mathrm{abc}$ & 10,118 \\
MS71 & $0.28 \mathrm{bcd}$ & 0.33 & & $8.21 \mathrm{abcde}$ & 3,689 \\
Oh43 & $0.27 \mathrm{bcd}$ & 0.31 & & $7.84 \mathrm{bcde}$ & 2,542 \\
Oh7B & $0.21 \mathrm{~cd}$ & 0.23 & & $8.16 \mathrm{abcde}$ & 3,483 \\
IBM54 & $0.11 \mathrm{~d}$ & 0.12 & & $7.93 \mathrm{bcde}$ & 2,790 \\
NC358 & $0.11 \mathrm{~d}$ & 0.11 & & $6.75 \mathrm{defg}$ & 854 \\
IBM262 & $0.09 \mathrm{~d}$ & 0.10 & & $8.75 \mathrm{abcd}$ & 6,283 \\
Ky21 & $0.08 \mathrm{~d}$ & 0.08 & & $6.96 \mathrm{defg}$ & 1,056 \\
Tx303 & $0.06 \mathrm{~d}$ & 0.06 & & $7.20 \mathrm{cdef}$ & 1,333 \\
Ki3 & $0.05 \mathrm{~d}$ & 0.06 & & $7.46 \mathrm{bcde}$ & 1,739 \\
Mp339 & $0.05 \mathrm{~d}$ & 0.05 & & $6.79 \mathrm{defg}$ & 886 \\
M37W & $0.02 \mathrm{~d}$ & 0.02 & & $6.43 \mathrm{efgh}$ & 622 \\
CML52 & $0.00 \mathrm{~d}$ & 0.00 & & $4.55 \mathrm{~h}$ & 94 \\
Mp313E & $0.00 \mathrm{~d}$ & 0.00 & & $4.84 \mathrm{gh}$ & 126 \\
CML247 & $0.00 \mathrm{~d}$ & 0.00 & & $5.15 \mathrm{fgh}$ & 172
\end{tabular}

${ }^{\mathrm{z}}$ Levels not connected by same letter are significantly different as determined by Tukey test $(\alpha=$ $0.05)$. 
account for the high correlation between infection levels and aflatoxin contents. Although the sources of resistance tested in the African maize germplasm may be different, it is possible that prior conclusions have been affected by the use of methods that do not permit accurate measurement of pathogen biomass. Interestingly, among our inbreds, the line IBM262 allowed high levels of aflatoxin contamination while the IC levels were undistinguishable from the most resistant lines. Currently, our inbreds are being tested again in the field to confirm our results. It is also possible that the environment has differential effects on fungal growth and aflatoxin biosynthesis. More studies are needed to further explore the effects of defined host genes on colonization and contamination of maize by A. flavus.

\section{ACKNOWLEDGMENTS}

This study was funded in part by The McKnight Foundation and the Generation Challenge Program. We thank E. Helliwell for advice on qPCR development and the Cornell Statistical Consulting Unit for advice on data analysis.

\section{LITERATURE CITED}

1. Bowman, J. C., Abruzzo, G. K., Anderson, J. W., Flattery, A. M., Gill, C. J., Pikounis, V. B., Schmatz, D. M., Liberator, P. A., and Douglas, C. M. 2001. Quantitative PCR assay to measure Aspergillus fumigatus burden in a murine model of disseminated aspergillosis: demonstration of efficacy of caspofungin acetate. Antimicrob. Agents Chemother. 45:3474-3481.

2. Brooks, T., Williams, W. P., Windham, G. L., Willcox, M. C., and Abbas, H. K. 2005. Quantitative trait loci contributing resistance to aflatoxin accumulation in the maize inbred Mp313E. Crop Sci. 45:171-174.

3. Brown, R. L., Brown Jenco, C. S., Bhatnagar, D., and Payne, G. A. 2003. Construction and preliminary evaluation of an Aspergillus flavus reporter gene construct as a potential tool for screening aflatoxin resistance. J. Food Prot. 66:1927-1931.

4. Brown, R. L., Chen, Z., Menkir, A., Cleveland, T. E., Cardwell, K., Kling, J., and White, D. G. 2001. Resistance to aflatoxin accumulation in kernels of maize inbreds selected for ear rot resistance in west and central Africa. J. Food Prot. 64:396-400.

5. Brown, R. L., Cleveland, T. E., Payne, G. A., Woloshuk, C. P., Campbell, K. W., and White, D. G. 1995. Determination of resistance to aflatoxin production in maize kernels and detection of fungal colonization using an Aspergillus flavus transformant expressing Escherichia coli $\beta$ glucuronidase. Phytopathology 85:983-989.

6. Busboom, K. N., and White, D. G. 2004. Inheritance of resistance to aflatoxin production and Aspergillus ear rot of corn from the cross of inbreds B73 and Oh516. Phytopathology 94:1107-1115.

7. Costa, C., Vidaud, D., Olivi, M., BartDelabesse, E., Vidaud, M., and Bretagne, S. 2001. Development of two real-time quantitative TaqMan PCR assays to detect circulating Aspergillus fumigatus DNA in serum. J. Microbiol. Methods 44:263-269.

8. Cotty, P. J., Bayman, P., Egel, D. S., and Elias, K. S. 1994. Agriculture, aflatoxins and Aspergillus. Pages 1-27 in: The Genus Aspergillus: From Taxonomy and Genetics to Industrial Application. K. A. Powell and J. F. Peberdy, eds. Plenum Publishing Corporation, New York.

9. Cruz, P., and Buttner, M. P. 2008. Development and evaluation of a real-time quantitative
PCR assay for Aspergillus flavus. Mycologia 100:683-690

10. Doyle, J., and Dickson, E. 1987. Preservation of plant samples for DNA restriction endonuclease analysis. Taxon 36:715-722.

11. Du, W., Huang, Z., Flaherty, J. E., Wells, K., and Payne, G. A. 1999. Green fluorescent protein as a reporter to monitor gene expression and food colonization by Aspergillus flavus. Appl. Environ. Microbiol. 65:834-836.

12. Flint-Garcia, S. A., Thuillet, A. C., Yu, J., Pressoir, G., Romero, S. M., Mitchell, S. E., Doebley, J., Kresovich, S., Goodman, M. M., and Buckler, E. S. 2005. Maize association population: a high-resolution platform for quantitative trait locus dissection. Plant J. 44:1054-1064.

13. Hedayati, M. T., Pasqualotto, A. C., Warn, P. A., Bowyer, P., and Denning, D. W. 2007. Aspergillus flavus: human pathogen, allergen and mycotoxin producer. Microbiology 153:1677-1692.

14. Heid, C. A., Stevens, J., Livak, K. J., and Williams, P. M. 1996. Real time quantitative PCR. Genome Res. 6:986-994.

15. Henry, S. H., Bosch, F. X., Troxell, T. C., and Bolger, P. M. 1999. Policy forum: public health. Reducing liver cancer-global control of aflatoxin. Science 286:2453-2454.

16. Henry, T., Iwen, P. C., and Hinrichs, S. H. 2000. Identification of Aspergillus species using internal transcribed spacer regions 1 and 2. J. Clin. Microbiol. 38:1510-1515.

17. Holmes, R. A., Boston, R. S., and Payne, G. A. 2008. Diverse inhibitors of aflatoxin biosynthesis. Appl. Microbiol. Biotechnol. 78:559-572.

18. Jayashree, T., and Subramanyam, C. 2000. Oxidative stress as a prerequisite for aflatoxin production by Aspergillus parasiticus. Free Radic. Biol. Med. 29:981-985.

19. Kim, J. H., Yu, J., Mahoney, N., Chan, K. L., Molyneux, R. J., Varga, J., Bhatnagar, D., Cleveland, T. E., Nierman, W. C., and Campbell, B. C. 2008. Elucidation of the functional genomics of antioxidant-based inhibition of aflatoxin biosynthesis. Int. J. Food Microbiol. 122:49-60.

20. Kumeda, Y., and Asao, T. 1996. Single-strand conformation polymorphism analysis of PCRamplified ribosomal DNA internal transcribed spacers to differentiate species of Aspergillus section Flavi. Appl. Environ. Microbiol. 62:2947-2952.

21. Liu, K., Goodman, M., Muse, S., Smith, J. S., Buckler, E., and Doebley, J. 2003. Genetic structure and diversity among maize inbred lines as inferred from DNA microsatellites. Genetics 165:2117-2128.

22. Marsh, S. F., and Payne, G. A. 1984. Scanning EM studies on the colonization of dent corn by Aspergillus flavus. Phytopathology 74:557-561.

23. Mayer, Z., Bagnara, A., Farber, P., and Geisen, R. 2003. Quantification of the copy number of nor-1, a gene of the aflatoxin biosynthetic pathway by real-time PCR, and its correlation to the cfu of Aspergillus flavus in foods. Int. J. Food Microbiol. 82:143-151.

24. Moreno, O. J., and Kang, M. S. 1999. Aflatoxins in maize: the problem and genetic solutions. Plant Breed. 118:1-16.

25. Munkvold, G. P. 2003. Cultural and genetic approaches to managing mycotoxins in maize. Annu. Rev. Phytopathol. 41:99-116.

26. Murray, S. R., Butler, R. C., Hardacre, A. K., and Timmerman-Vaughan, G. M. 2007. Use of quantitative real-time PCR to estimate maize endogenous DNA degradation after cooking and extrusion or in food products. J. Agric. Food Chem. 55:2231-2239.

27. Paul, C., Naidoo, G., Forbes, A., Mikkilineni, V., White, D. G., and Rocheford, T. 2003. Quantitative trait loci for low aflatoxin production in two related maize populations. Theor. Appl. Genet. 107:263-270.

28. Raidl, S., Bonfigli, R., and Agerer, R. 2005. Calibration of quantitative real-time TaqMan
PCR by correlation with hyphal biomass and ITS copies in mycelia of Piloderma croceum. Plant Biol. (Stuttgart) 7:713-717.

29. Rajasekaran, K., Cary, J. W., Cotty, P. J., and Cleveland, T. E. 2008. Development of a GFPexpressing Aspergillus flavus strain to study fungal invasion, colonization, and resistance in cottonseed. Mycopathologia 165:89-97.

30. Scheidegger, K. A., and Payne, G. A. 2003. Unlocking the secrets behind secondary metabolism: a review of Aspergillus flavus from pathogenicity to functional genomics. J. Toxicol. 22:423-459.

31. Schena, L., Hughes, K. J. D., and Cooke, D. E. L. 2006. Detection and quantification of Phytophthora ramorum, P. kernoviae, $P$. citricola and $P$. quercina in symptomatic leaves by multiplex real-time PCR. Mol. Plant Pathol. 7:365-379.

32. Scott, G. E., and Zummo, N. 1990. Registration of Mp313E parental line of maize. Crop Sci. 30:1378-1378

33. Shephard, G. S. 2008. Impact of mycotoxins on human health in developing countries. Food Addit. Contam. 25:146-151.

34. Smart, M. G., Wicklow, D. T., and Caldwell, R. W. 1990. Pathogenesis in Aspergillus ear rot of maize light microscopy of fungal spread from wounds. Phytopathology 80:1287-1294.

35. Thompson, J. D., Gibson, T. J., Plewniak, F., Jeanmougin, F., and Higgins, D. G. 1997. The CLUSTAL_X windows interface: flexible strategies for multiple sequence alignment aided by quality analysis tools. Nucleic Acids Res. 25:4876-4882

36. Tucker, D. H., Trevathan, L. E., King, S. B., and Scott, G. E. 1986. Effect of four inoculation techniques on infection and aflatoxin concentration of resistant and susceptible corn hybrids inoculated with Aspergillus flavus. Phytopathology 76:290-293.

37. Valsesia, G., Gobbin, D., Patocchi, A., Vecchione, A., Pertot, A., and Gessler, C. 2005. Development of a high-throughput method for quantification of Plasmopara viticola DNA in grapevine leaves by means of quantitative realtime polymerase chain reaction. Phytopathology 95:672-678.

38. Widstrom, N. W., Butron, A., Guo, B. Z., Wilson, D. M., Snook, M. E., Cleveland, T. E., and Lynch, R. E. 2003. Control of preharvest aflatoxin contamination in maize by pyramiding QTL involved in resistance to ear-feeding insects and invasion by Aspergillus spp. Eur. J. Agron. 19:563-572.

39. Wild, C. P. 2007. Aflatoxin exposure in developing countries: the critical interface of agriculture and health. Food Nutr. Bull. 28:S372-380.

40. Williams, J. H., Phillips, T. D., Jolly, P. E., Stiles, J. K., Jolly, C. M., and Aggarwal, D. 2004. Human aflatoxicosis in developing countries: a review of toxicology, exposure, potential health consequences, and interventions. Am. J. Clin. Nutr. 80:1106-1122.

41. Williams, W. P., and Windham, G. L. 2001 Registration of maize germplasm line Mp715. Crop Sci. 41:1374-1375.

42. Williams, W. P., and Windham, G. L. 2006. Registration of maize germplasm line Mp717. Crop Sci. 46:1407-1408.

43. Williams, W. P., Windham, G. L., and Buckley, P. M. 2008. Diallel analysis of aflatoxin accumulation in maize. Crop Sci. 48:134-138.

44. Windham, G. L., and Williams, W. P. 2002. Evaluation of corn inbreds and advanced breeding lines for resistance to aflatoxin contamination in the field. Plant Dis. 86:232-234.

45. Yu, J., Holland, J. B., McMullen, M. D., and Buckler, E. S. 2008. Genetic design and statistical power of nested association mapping in maize. Genetics 178:539-551

46. Zhang, Y., Kang, M. S., and Magari, R. 1997. Genetics of resistance to kernel infection by Aspergillus flavus in maize. Plant Breed. 116:146-152. 